\title{
NARRATIVAS E DESENHOS NO ENSINO DE ASTRONOMIA/GEOCIÊNCIAS COM O TEMA "A FORMAÇÃO DO UNIVERSO": UM OLHAR DAS GEOCIÊNCIAS
}

\begin{abstract}
RESUMO: A partir das Geociências, o artigo problematiza para o ensino de Astronomia, se a complexidade do objeto e dos fenômenos em Astronomia necessita do uso da linguagem visual em compartilhamento com a linguagem verbal, ou seja, se necessita da integração do verbal (narrativo) e do não-verbal (expressões gráficas - desenho). Retiro de um estudo de caso para as discussões duas estórias com dois desenhos sobre a formação do Universo. Mostro que os alunos desenvolveram "conceitos visuais", para singularizarem fenômenos do tema, e a lógica narrativa em que as partes foram conformadas, tendo em vista uma noção da estória final. Essas discussões estão apoiadas na semiótica pierciana para as narrativas e nos estudos de percepção visual (Gestalt).

Palavras-chave: Ensino de Astronomia; Narrativas Históricas; Desenhos.

\section{NARRATIVES AND DRAWINGS IN ASTRONOMY/GEOSCIENCES \\ TEACHING ON THE THEME "THE FORMATION OF THE UNIVERSE": FROM GEOSCIENCES POINT OF VIEW}

ABSTRACT: For the teaching of Astronomy, the article disputes if the complexity of the object and the phenomena in Astronomy require the use of visual language together with the verbal language, that is: if it requires verbal integration (narration) and the non-verbal one (graphicdesign expressions). For the discussion, I extract two stories with two drawings from a case study on the Formation of the Universe. I show the students that they have developed "visual concepts", to single out phenomena on the theme and the narrating logic, in which the parts were conformed having in view a notion of the final story. These discussions are supported by the Piercian semiotic for the narrations; and by the studies of visual perception (Gestalt).

Keywords: Astronomy Teaching; History Narratives; Graphic-design; Expressions.
\end{abstract}




\section{Introdução}

Este artigo discute o uso de desenhos e de narrativas para ensinar Astronomia/Geociências ${ }^{1}$ no terceiro ciclo ( $6^{\circ}$ e $7^{\circ}$ anos) do ensino fundamental. Essas práticas e reflexões venho fazendo a partir do meu mestrado (COMPIANI, 1988) e foi com o doutorado que experienciei como professor meus problemas e hipóteses de pesquisa e desenvolvi especificamente o tema de Astronomia sob um olhar das Geociências. As discussões sobre o discurso narrativo e os desenhos venho até hoje pesquisando e boa parte dessas reflexões mais atuais, que servem para o tema de Astronomia, estão nesse artigo. Para essa discussão com outros temas das geociências ver Compiani (2000 e 2006). O problema que continuo pesquisando é se a complexidade do objeto e do fenômeno em Astronomia e Geociências solicita o uso da linguagem visual e força um compartilhamento desta com a linguagem verbal, ou seja, se necessita da integração do verbal (narrativo) e o não-verbal (expressões gráficas - desenho). Por tratar-se de artigo temático, os dados referem-se ao meu doutorado (COMPIANI, 1996) que foi sobre o ensino do tema "A Formação do Universo" na disciplina de Geografia para 18 alunos de 10 a 12 anos, $5^{\text {a }}$ série de uma escola pública de Jundiaí-SP. Transpasso para esse artigo, discussões mais atualizadas que vêm sendo feitas com temas mais geocientíficos como ciclo da água, paisagens geocientíficas, bacia hidrográfica etc. desenvolvidos em projetos com os professores da escola pública.

Pedagogicamente, venho demonstrando que as Geociências (com esse artigo, acredito que a Astronomia tem o mesmo papel) terão papel de destaque neste novo enfrentamento de valorizar a intuição, a imaginação e a criatividade, tão esquecidas no ensino de ciências. A necessidade de enfrentar o lado intuitivo e criativo na educação já é bastante antiga, porém no ensino de ciências começou a aparecer com mais intensidade na década de 80. Segundo Hodson (1985), na prática científica, conceitos e teorias são produzidos por atos criativos de abstração e invenção, mas, no ensino de ciências, a ênfase é posta nas experimentações e esquece-se a fase criativa individual tão fundamental na prática científica para equacionar os problemas, formular hipóteses etc. Novak (1988) discutindo a criação do conhecimento finaliza a discussão ressaltando a criatividade: "Agora a saída parece estar mais em como facilitar a produção criativa do que em fixar os critérios de provas e refutação" (NOVAK, 1988, p. 35).

Para Vygotsky (1990), os indivíduos são potencialmente dotados para a criatividade e será o ambiente sócio-cultural que poderá incentivar tal potencialidade. A imaginação e a criatividade representam um complexo e contínuo processo de reestruturação da informação que um indivíduo é capaz de realizar, desde a infância, frente à sua relação com o meio natural e social. Em relação à tradicional visão sobre a atividade criativa, comumente atribuída a poucos indivíduos eleitos e vista como uma exceção entre os mortais, o autor rompe com essa visão quando afirma que a criatividade é uma regra na vida cotidiana, é uma 
condição indispensável à existência, pois tudo o que vai além dos limites da rotina, que tem algo de novo, deve a sua origem à criatividade.

Se entendermos a criatividade deste modo, ficará fácil ver sua importância desde muito cedo no desenvolvimento infantil. A capacidade de dar formas, com os elementos disponíveis, a uma determinada construção, de combinar o velho em uma nova união, conjunto ou até síntese, constitui o fundamento da criatividade. A esta atividade criativa algumas áreas da psicologia dão o nome de imaginação.

Somam-se a isso as últimas pesquisas, mostrando o reinado da linguagem ou de uma cultura escrita no contexto educacional (WERSTCH \& MINICK, 1988; PONTRCORVO et al 1992). É importante refletir sobre isso e pesquisar novas linguagens como pretendo mostrar neste artigo. Discutir alternativas ao reinado da escrita é fundamental para abrirmos nosso olhar para novas potencialidades da cognição e do contexto escolar, principalmente, para nós, geocientistas, que sabemos da relevância no ensino de Geociências da abstração, das narrativas históricas, dos raciocínios visuais e espaciais e do uso de analogias e modelos.

No sentido de quebrar o domínio da linguagem verbal na escola, tenho levado adiante o desafio de tratar o entrelaçamento entre linguagem visual e verbal. Em relação às narrativas utilizo os estudos de Frodeman (1995) no campo da teoria da Geologia e os estudos no campo da semiótica pierciana. No tocante ao olhar para a linguagem visual, notadamente, as expressões gráficas dos alunos, busco subsídios teóricos na Percepção Visual com destaque para a Gestalt (ARNHEIM, 1980 e 1987) e vejo ligações desse autor com as ideias de Vickers (1979) no campo das Artes; desse ponto de vista, apoio-me na discussão sobre intuição versus racionalidade. É essa sequência da linguagem verbal para a visual, da narrativa para os desenhos que desenvolvo no artigo, mas sem perder de vista a interdependência, a natureza verbo-visual dos conhecimentos geocientíficos e astronômicos. Desse modo, a matéria-prima do artigo são as narrativas desenhadas e os desenhos narrados, isto é, construtos verbo-visuais e visual-verbais feitos pelos alunos sobre o tema de estudo "A Formação do Universo".

\section{A narração e o desenho como discursos no ensino de Geociências}

Dando continuidade às ideias de Paschoale (1989 e 1990), venho defendendo que a criatividade e a imaginação são necessárias para a prática geológica. Inicialmente essa defesa foi mais teórica, com argumentos dentro do campo da filosofia e epistemologia, buscando diferenciar e valorizar as especificidades da Geologia frente às ciências clássicas como a Física e a Química. Nesse sentido, um marco é a dissertação de mestrado do Paschoale (1989): “Geologia como semiótica da Natureza". Vieram em seguida dois trabalhos, Compiani (1990) e Compiani \& Paschoale (1990), também ainda teóricos, mas já buscando 
abordar para o ensino aquelas ideias da Geologia como ciência histórica da natureza. Agora, este meu artigo, que é parte de pesquisas de conteúdos específicos em educação, no caso Geociências e Astronomia, é uma das possíveis aplicações daquelas ideias. Foi realizado junto a uma classe de alunos de 11 a 12 anos. Como esses alunos quiseram aprender sobre a formação do Universo, eu enveredei para o ensino de Astronomia. Ao lidar com esse tema percebi que a narrativa e o desenho são formas de discurso importantíssimas para justamente desenvolver a criatividade e imaginação no ensino de Astronomia e, por decorrência, no de Geologia.

Naqueles trabalhos (COMPIANI, op. cit.; COMPIANI \& PASCHOALE, op. cit.), havia a ênfase nos aspectos histórico-comparativos e, por decorrência, nos raciocínios analógicos. Já estava apontada também a relevância da linguagem visual. Tínhamos em mente detalhar as cognições importantes de um campo de conhecimento específico para adequá-lo ao hipotético desenvolvimento cognitivo dos alunos. Quando fui aplicar essas ideias à uma classe concreta, verifiquei o grande instrumental que tinha, mas era insuficiente, e me dei conta da enorme importância da mediação do professor e do discurso em uma sala de aula, dentre este, do discurso científico. Assim, pude ampliar a minha ênfase inicial apenas nos raciocínios analógicos para as narrativas históricas e começar a aplicar as nossas ideias sobre os raciocínios visuais e espaciais com os desenhos. Como explico no texto corrido, enveredo, na medida do necessário, para compreender a percepção visual sob o ponto de vista da 'Gestalt'.

Astronomia e Geologia são ciências históricas e são constituídas, essencialmente, por fenômenos que apresentam desenvolvimento histórico. A Astrofísica se enquadra em outro marco epistemológico. Uma história é repleta de acontecimentos individuais imprevisíveis, mas, sobretudo que não se repetem e não podem ser reversíveis. Por isso, nessas ciências os raciocínios mais significativos não são os hipotético-dedutivos e sim a formulação de hipóteses pelos raciocínios históricos.

Entre os filósofos da ciência, Frodeman (1995), tem sido para mim, um dos primeiros a discutir a importância do discurso científico em Geociências. Desse modo, Frodeman (op. cit.) afirma que as ciências históricas são distinguidas pelo decisivo papel da lógica narrativa em suas explanações. Para o autor, a narrativa lógica é um tipo de entendimento em que os detalhes adquirem sentido na estrutura geral da história, no senso que, por meio do narrar uma história, nós criamos um contexto temporal e espacial em que as partes da história estão constituídas e são relacionadas com o todo dessa história.

O discurso histórico dos geocientistas visa explicar como ocorreu um evento do passado da Terra por meio de 'marcas' observáveis do evento, que supomos ser evidências ligadas aos processos ocorridos. Ou seja, partimos dos produtos, dos efeitos de um acontecimento para buscar as suas causas. É essa racionalidade do efeito para a causa que foi exercitada com os alunos da escola pública de Jundiaí. 
Ainda sobre o discurso narrativo, é importante assinalar algumas ideias que utilizei da semiótica pierciana a partir dos trabalhos de Santaella Braga (1980) e Machado et al (1984). Os autores partem do que dizem ser a tradicional divisão do discurso em descrição, narração e dissertação para aprofundarem e sugerirem reformulações. Para os autores, na narração, como a própria palavra indica, o elemento principal é a ação: 'narra-ação'. Trata-se, assim, do registro linguístico de eventos ou situações de acontecimentos singulares em termos de agente/paciente e causa/efeito. Definem o discurso narrativo sucessivo como a apresentação sequencial ou cronológica das partes de um dado evento, é o caso típico das crônicas onde o acontecimento é relatado no seu encadeamento temporal. Já o narrativo causal apresenta um fenômeno por meio de suas causas, de suas condições de funcionamento, isto é, um determinado evento é relacionado a fatos, estabelecendo-se relações de causa e efeito de implicações lógicas e muitas vezes juízos avaliativos e não apenas cronológicas. Definem o discurso narrativo sucessivo-causal, como aquele que apresenta um evento mostrando seu desenvolvimento através do tempo e procurando explicá-lo em termos de causalidade, ou seja, apresenta uma lógica em que os detalhes, ao serem narrados vão se constituindo em partes integradas e justificadas por 'causação' na estrutura geral da explanação histórica. Este é um tipo de discurso geocientífico e histórico. Defendo que essa noção de sucessão no tempo e de implicações causais de um evento é importante para ser exercitado já com alunos de $6^{\circ}$ ano do ensino fundamental.

Quando, no ensino de ciências, são utilizados desenhos, a justificativa básica é fazer emergir aqueles indícios interpretáveis que não apareceriam caso a expressão fosse apenas escrito/verbal. Por vários motivos, acredita-se que as crianças apresentam limitações para verbalizar suas ideias e, principalmente, escrevê-las. Os escritos e as falas não são suficientes para expressar tudo o que elas pensam, daí a necessidade de ampliar os modos de expressão.

Mesmo do ponto de vista do ensino de ciências, parece-me restrito o uso de desenhos apenas para ampliar o modo de expressão das crianças. Essa é uma postura que reforça o reinado da linguagem verbal na escola. As crianças apresentam limitações do desenvolvimento cognitivo, tanto em relação ao verbal quanto ao não-verbal. É notório crianças que se expressam bem verbalmente, mas não desenham quase nada por deficiências de representação da perspectiva, da passagem da tridimensionalidade (o mundo) para a bidimensionalidade (o papel) e vice-versa. Para uma proposta didática de interação/comunicação com ênfase na utilização de conceitos abstratos e de modelos, a função dos signos verbais e não-verbais é relevante. Trabalhar com o não-verbal traz, provavelmente, muito mais problemas de interpretações das ideias das crianças, o que é um desafio interessante, que, erradamente pensam-se, auxílios no desvendar das limitações da escrita.

A incorporação da linguagem visual no processo de ensino-aprendizagem poderia clarear ou, até mesmo, propiciar uma crítica ao uso corriqueiro, na 
escola, de recursos descontextualizados, ou seja, a apresentação de conceitos e generalizações sem conexão direta com os respectivos objetos singulares. Exemplificando: a imagem de um granito revela a mediação entre um corpo rochoso singular e o conceito de granito. Pois, temos a configuração de um ou alguns granitos que nos dá indícios das propriedades do enunciado granito. Normalmente, em um texto que discute sobre granitos, a descrição de um corpo rochoso particular é feita por uma série de generalizações, que não revelam a mediação entre os granitos existentes e o conceito (enunciado) de granito (PASCHOALE, 1984).

$\mathrm{O}$ verbal e o visual são de importância vital nas Geociências. $\mathrm{O}$ visual e o verbal têm a capacidade de possibilitar, mais facilmente, a mediação do singular que a imagem potencialmente representa, com o enunciado que o verbal representa. É interessante o exercício de apreensão de um objeto, pois é indissociável o visual do verbal. Voltando então, às noções que Paschoale (op. cit.) apontou ao mostrar a mediação, por exemplo, do enunciado granito com a imagem de um granito. Percepção e concepção deste granito passarão pela imagem e pelo espacial. Dependendo da foto, do ângulo etc., o granito estará representado pelos elementos visíveis. $\mathrm{O}$ esquema visual daquele granito será único. $\mathrm{O}$ visual, desse modo, realça a função indiciante dos signos, mostra o granito que o signo redobra ("granito" significa este granito e não outro). Perceber e conceber o granito passará também pelo verbal. Ao mesmo tempo, o granito nos fala sobre o seu individual, como também nos instrui sobre todos os granitos. O verbal, assim, tem função simbólica de representar o objeto na sua ausência, visa o objeto na sua generalidade (este granito é um 'granito' entre outros). Segundo Pino (1991), a indissociabilidade anterior está relacionada com os processos de contextualização/descontextualização. Esta torna os significados representantes de totalidades genéricas, ao contrário, aquela, a contextualização confere aos significados das palavras uma significação concreta e particularizada. Nesse artigo essas discussões são exemplificadas e interpretadas com dados de narrativas e desenhos sobre a formação do Universo.

No ensino de Geociências, o reinado do pensamento verbal dificulta sua aprendizagem. Já foi devidamente apontado por Paschoale (1984, 1988, 1989 e 1990), Pedemonte \& Bezzi (1989) e Bezzi (1995 e 1996) o intenso uso de índices (vestígios), ícones (imagens) e símbolos (verbal e não-verbal) para formular os construtos em Geologia. Por isso, desenvolverei, um pouco, a seguinte pergunta: o desenho é fundamental na compreensão dos conceitos geológicos?

Vou utilizar as ideias de Leveson (1988) no seu artigo "The Geologist's Vision". O autor, em uma parte de seu artigo, discute como um geólogo vê a essência de uma rocha. Posso extrair de suas ideias que o geólogo as experiencia como rochas - uma realização que implica alguma ligação com as rochas verdadeiras. É este o vínculo que diferentes imagens dividem. Rochas verdadeiras tornaram-se arquétipos das quais os símbolos e os enunciados sobre as rochas se aproximam. É um raciocínio semelhante ao de Paschoale (1984) com o exemplo do granito que acabei de escrever. Para Leveson: 
Em resumo, o discernimento de padrões pode não ser fácil. Parece que o instinto requer um amparo e ele existe. Há uma abordagem para o padrão que o encontra em seus próprios termos, uma abordagem que, felizmente, não requer nenhuma instrumentação cara, complexa, mas, somente um lápis e um bloco de papel: o domínio das rochas pode ser obtido pela experiência simples do desenho (LEVESON, 1988, p. 308).

O autor justifica suas ideias. Para desenhar ou criar um esquema, devese olhar, ver e tomar decisões. Uma imagem desenvolve-se. Existe um contínuo questionamento e resposta, avaliação e reavaliação. É pelo desenho que alguém aprende a discernir e que a visão torna-se acurada.

Parece claro que apenas a linguagem escrita não dá conta da complexidade das representações das explicações em Geociências. Sobretudo, as escalas espaciais gigantescas colocam fortes limitantes para a utilização apenas da escrita. Por isso, a linguagem visual e o raciocínio espacial têm importância destacada na Geologia e, por extensão, na Astronomia.

$\mathrm{O}$ autor continua discutindo que, embora o discernimento de padrão possa ser obtido por meio do desenho, o problema da integridade na seleção de dados permanece. Como foi mencionado, hipóteses acerca da origem das rochas desempenham decisivo papel na análise minuciosa dos elementos do padrão potencial os quais são necessários ao reconhecimento e aceitação dos padrões eventuais e assim, o padrão é citado como apoio à hipótese da origem. Então, Leveson pergunta: Como tal circularidade pode ser desculpada? Sua resposta é clara:

Talvez não, mas eu suspeito que ela seja inevitável (...) porque nenhuma criatura pode existir neste Universo sem o abrigo da discriminação. Mais uma vez, o que emerge no papel depende, em grande parte do que, através dos filtros da bagagem anterior e da teoria, é esperado, assim como, da maneira e da habilidade de passar da visão a alguma coisa tangível (LEVESON, 1988, p. 308).

Ainda, segundo Leveson,

Para um olho experimentado, o padrão é resultado de um evento deformacional que ocorreu sobre determinadas condições. Entretanto, a ligação visível entre o material e o ambiente deformacional não pode ser convenientemente exposta em fórmulas matemáticas exatas ou localizada precisamente em limites geométricos, daí, mais uma vez, nós estarmos trazendo à tona a arte geológica. O que se requer é uma educada mas, em última instância, avaliação intuitiva de diversos elementos (LEVESON, 1988, p. 308).

Eu pergunto, como é possível salientar o objeto do processo? Como se cria a representação do espaço e a profundidade? Estes problemas serão mais facilmente enfrentados se o professor encorajar seus alunos a usarem a inteligência e a imaginação, exercitando o uso da intuição, ao apelo a truques mecânicos. O intuitivo está mais ligado à percepção visual e à representação espacial. É o 
lado intuitivo que lida mais facilmente com o contexto, com a estrutura global, com a forma, o fundo e o contorno. Por isso, acredito que a realização de atividades com padrões espaço-temporais, modelizações são fundamentais para a formação dos alunos.

Esclareço algumas ideias sobre a intrincada dialética entre o racional e o intuitivo. Arnheim (1987) defende que a intuição e a racionalidade são dois procedimentos próprios da cognição e esta é um continuum que vai da percepção imediata até os construtos teóricos mais elaborados. Para o autor, as capacidades que normalmente vêm atribuídas à racionalidade - aquela de distinguir, de confrontar, de delimitar e, assim por diante - operam já na percepção elementar. Ao mesmo tempo, cada ato do pensamento solicita uma base sensorial.

É interessante acrescentar outro autor Vickers (1979), que associado à Arnheim (op. cit.), afirmam que existam, pelo menos, dois principais modos de conhecimento: a racionalidade e a intuição. Um indivíduo usa ambas em apropriadas (ou não) combinações, no seu esforço interminável para conhecer o mundo, no qual ele se encontra. Para Vickers, a racionalidade é mais dependente da análise, raciocínio lógico, cálculo e descrição explícita; já a intuição é mais dependente da síntese e reconhecimento de padrão, do contexto, das relações entre componente singular e outros aspectos da organização perceptiva e das múltiplas possibilidades de relações entre figura e fundo. Para Arnheim (op. cit.), a análise racional serve para abstrair do contexto individual suas características de elemento e evento, buscando a generalização para propiciar a classificação; já a intuição fornece a estrutura global de uma situação e determina a posição de cada elemento internamente ao global. Recolocando as ideias, são dois modos de pensar indissociáveis: o primeiro (lógico) envolve a abstração e a manipulação de elementos sem considerar as formas às quais estão combinados; o outro (perceptivo) envolve o reconhecimento ou a criação de formas, sem considerar os elementos que as compõem. ${ }^{2}$

Nas ciências históricas, a generalização é diferente das não históricas, como a Física, por exemplo, nestas os conhecimentos universais perdem de vista o contexto (espaço/tempo), o referente que originou a generalização, assim os significados são representantes de totalidades genéricas. Naquelas as generalizações nunca perdem o contexto de referência, apesar da maior descontextualização dessas tendências históricas, elas são as generalizações da periodização histórica e síntese espacial.

Complementando um pouco mais as ideias sobre a Geologia, ela é casada, em última instância, com o visual, com a história, como já pude mostrar por meio de Leveson (1988). Segundo Paschoale (1990), uma explicação histórica é apenas suposta, não é demonstrável experimentalmente. Em outras palavras, a explicação geológica é hipotética no sentido do possível: a relação entre causa e efeito não é conhecida, mas apenas suposta. ${ }^{3} \mathrm{O}$ processo de hipotetização supõe que o registro (evidência) é um produto de um processo passado, ou seja, as evidências apontadas servirão para a estruturação das hipóteses. 
O que direciona o olhar do geólogo são as assunções, as hipóteses e teorias para desvendar a história da Terra. Na natureza, os processos passados quando resistem à erosão, denudação etc., deixam formas. Como estas formas passam a ser 'formas fixadas', ou seja, vestígios, registros do processo passado?

Sabemos que a explicação se faz a partir de uma série de marcas observáveis, e as mesmas só podem ser estudadas por associações e semelhanças com outras feições. Duas cognições são importantes: primeiro, a forma deve ser identificada como significativa e, para isso, é operado todo um arcabouço de experiências passadas entre feições e informações de processos contemporâneos para capacitar a mente observadora-interpretadora a perceber que tais feições são indicativas (são índices de uma relação físico-existencial apontando para seu objeto de que ele é parte) de um processo passado. A outra cognição, então, é transformar esta forma em 'forma fixada', ou seja, num símbolo que constitui as relações de causa de sua origem. Esta divisão em duas cognições é artificiosa, porém é importante reter que a procura do registro já direciona as duas cognições. A primeira cognição é mais descritiva e, com o apoio das ideias de Leveson, posso afirmar que é aquela em que o desenho é fundamental para o discernimento de algum padrão. A segunda cognição é mais explicativa; a utilização do padrão discernido serve para dar 'base fatual' à formulação de hipóteses que transformem as formas em evidências de supostas causas de suas origens. Por exemplo, por meio de observações astronômicas identificou-se um padrão de explosões (Supernovas) e aglomerações (sistemas estelares em formação); é este padrão que é utilizado para a elaboração da hipótese explicativa e do modelo (que eu utilizo na aula) da formação do Universo, o que, por sua vez, enquadra em um corpo teórico as próprias evidências que foram e são apoios para a teoria.

No ensino de Geociências, o desenho é uma forma de expressão corriqueira. Pois, o recurso visual amplia as possibilidades de se trabalhar com a dimensão gigantesca do espaço e tempo. Também, de se trabalhar a grande variedade de escalas observáveis (da micro à macro até à astronômica), onde temos uma gama enorme de formas diversas que vão desde o Universo visível, a Terra, os continentes, suas estruturas, rochas, minerais até a estrutura cristalina e química da matéria. Fora isto, temos o problema que as Geociências compartilham com todas as outras ciências, que é o da representação das explicações que, normalmente, é apresentada em duas dimensões (o papel), quando sabemos que o mundo se apresenta em três dimensões com, pelo menos, mais uma outra quarta dimensão: o tempo. Orion (1996) discute e aponta vários caminhos para se trabalhar essas questões em sala de aula. A complexidade do objeto e do fenômeno em Geociências e em Astronomia, sob essa ótica, solicita o uso da linguagem visual em compartilhamento com a linguagem verbal.

Ao enfrentar o ensino do tema "A Formação do Universo" foi ficando clara a relevância da narrativa e do desenho. Os próprios alunos deram-me uma pista para o casamento entre o verbal (narrativo sucessivo-causal) e o não- 
verbal (desenho). A pista foi a História em Quadrinhos (HQ) que, alguns deles utilizaram para realizar as tarefas de sala de aula.

Segundo Cagnin (1975), a HQ é uma forma narrativa por meio de imagens fixas. É um sistema narrativo formado por dois códigos de signos gráficos: a imagem, obtida pelo desenho e a linguagem escrita. A linguagem escrita tem um papel mais descritivo no sentido de conduzir a narrativa, já os desenhos se incumbem de singularizar e concretizar a narrativa por meio de personagens, cenários e movimento. Segundo o autor, fica mais fácil compreender a função de complementaridade dos sistemas envolvidos na HQ. O elemento verbal tem amplo poder de representação no vasto campo das classes conceituais, já o elemento visual está revestido da imensa riqueza da representação do real com características individuais.

Segundo Cagnin (op. cit.), o quadrinho transforma-se em uma unidade narrativa mínima, pois uma imagem ou figura é desenhada ou percebida num quadrinho, que lhe serve de fundo. Também, podemos inferir a sequência cronológica e a continuidade espacial entre os quadrinhos. Esta cognição é feita pelo leitor de quadrinhos que é praticamente co-autor da história, pois, segundo Lovreto (1993), o quadrinho mostra uma sequência intercalada por espaços vazios, onde nosso cérebro cria as imagens de ligação; entre um quadrinho e outro, o movimento tem continuidade na cabeça do leitor. Nos desenhos de meus alunos, a trama das relações de causalidade é expressa pelo visual e pela escrita; esta passa a ser tipicamente uma legenda, um elemento externo à ação, como uma voz quase impassível do narrador.

O problema é mostrar como, da significação de cada quadrinho, nasce a significação da sequência. Como para o leitor, ao se juntarem dois ou mais quadrinhos, estabelece-se uma comparação entre formas percebidas na leitura de cada uma. A própria ordem da leitura das imagens, uma após a outra, gera o conceito de tempo, de sucessão, de um antes e outro depois. Seria o que venho discutindo, no discurso verbal, como narrativo sucessivo. Já a relação lógica de causa e efeito não é dada apenas pela leitura sucessiva, como Cagnin acredita. A causalidade é de caráter implicativo, constituindo o narrativo causal que necessita e, vai além do sucessivo. Para análise do narrativo causal, é necessária a leitura e releitura de todos os quadrinhos dando a devida atenção às legendas, bem como da própria narrativa escrita. Ou seja, o causal se liga ao contexto e à compreensão do todo narrativo.

A intuição e racionalidade são os pilares para a análise que farei das narrativas e desenhos mostrando a criatividade com que os dois alunos foram construindo sem perder de vista a estória final, ou seja, a síntese da estória a ser narrada nunca foi perdida de foco para as articulações das partes, dos agentes e dos processos da estória, e nisso a intuição da estória toda foi sendo articulada pela racionalidade, que auxiliou no detalhe e particularidade com que os desenhos singularizaram os fenômenos e as narrativas, dando fluidez ao percurso à estória da formação do Universo. 


\section{Exemplificando com o estudo de caso sobre "A Formação do Universo"}

A experiência de sala de aula seguiu algumas etapas ${ }^{4}$ e sobre o conteúdo, eu decidi enfocar mais os processos de formação do Universo do que a caracterização dos elementos do Universo e propiciaria as definições no decorrer das discussões. Foi a leitura do livro de Rodríguez, Villa \& Anguita (1990) que me inspirou a formular os dois conceitos organizadores (auxiliam a organizar as ideias dentro de um campo de validade dos conhecimentos que estão sendo ensinados), que também são os dois principais processos que ocorrem no Universo. Os conceitos são: os processos explosivos, como o que deu origem ao Universo e à formação de Supernovas e os processos gravitacionais, como os que atuam na formação das galáxias e sistemas estelares. Assim, dentro dessa preocupação mais processual, pretendia trabalhar, num primeiro momento, com a narrativa sucessiva-causal, com as escalas espaciais astronômicas e, num segundo momento, com um modelo explicativo dos processos de formação do Universo que enfatizava um padrão espaço-temporal dos fenômenos.

Para o meu intento neste artigo, acredito seja necessário relembrar alguns aspectos da atividade 3 (aula debate) e da atividade 4 (produção dos alunos: narração e desenho). A aula debate possui três partes. A primeira parte da aula foi sobre o conceito organizador dos processos explosivos, ou seja, discutiu-se não apenas que o início do Universo se deu por meio de uma explosão, mas, sobretudo, o que explodiu e os efeitos da explosão; na segunda parte foi trabalhado o papel da atração gravitacional na formação das galáxias, em outras palavras, debateu-se sobre o conceito organizador de processos gravitacionais. Finalmente, na terceira parte foram iniciadas as discussões sobre a origem do Sistema Solar, porém os debates acabaram migrando para a formação da Terra.

Na segunda parte da aula debate, para a compreensão da formação das galáxias, foi utilizado o modelo, a seguir. O modelo foi introduzido com a intenção de facilitar o entendimento da formação das galáxias e o respectivo papel da atração gravitacional nesse fenômeno:

Figura 1: Modelo utilizado pelo professor para desenvolver as ideias sobre formação de uma galáxia

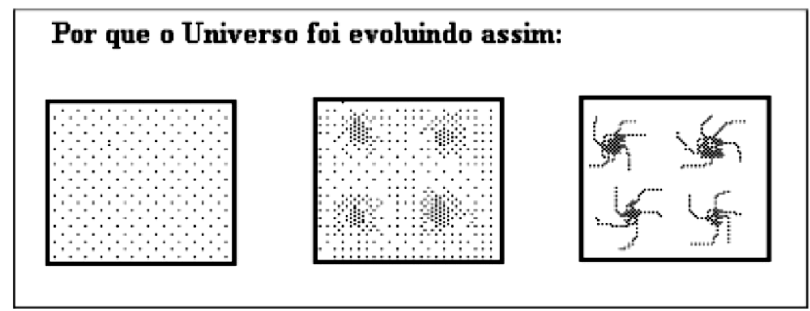


A omissão do primeiro quadrinho da explosão inicial (Figura 2) foi intencional. Sabia que a colocação desse quadrinho, por ser uma boa representação do padrão explosão $\rightarrow$ expansão, poderia direcionar muito o pensamento da classe e fechar prematuramente o convívio das ideias dos alunos com a do professor.

Figura 2: Símbolo de divergência que hipoteticamente representa o início do BIG-BANG

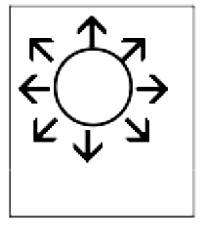

O modelo tem, por trás, uma teoria científica que busca explicar a formação do Universo. Ele expressa simplificadamente algumas das ideias implícitas na teoria, que envolve dois processos principais: explosão-expansão $\rightarrow$ atração gravitacional-aglomeração. Ele sintetiza em representações os dois conceitos organizadores da aula, a saber: processos explosivos e gravitacionais ${ }^{5}$.

Com o modelo tenho uma preocupação mais específica, idêntica à expressada por Massa (1994). Pensamos que nos estudos de muitos dos fenômenos naturais, é importante partir da explicitação do objeto ou fenômeno ou de sua representação em sua globalidade possível para proceder à análise das partes. Parti da percepção global inicial do modelo para depois caminhar para um processo de deciframento das partes em relações de causa/efeito. $\mathrm{O}$ apoio teórico expressei com a discussão da intuição e racionalidade. A intuição mais sintética, contextualizada e perceptiva se integra com a racionalidade mais analítica, descontextualizada e enunciativa. Defendo essas ideias, porque não me convencia mais a noção indutivista de que é necessário chegar às generalizações sempre a partir da observação das partes ou de membros individuais de um objeto ou fenômeno. O centro do artigo está aqui. Acredito que demonstro essas ideias com dados e discussões.

Acho difícil admitir que o aluno aprenda fundamentalmente pelo método indutivo: que ele olhe, manipule, observe, compare, raciocine e conclua; que as generalizações sejam elaboradas sempre a partir de casos singulares e que, de parte em parte, se torna cognoscível o todo. Gostaria de ressaltar a ideia de que um primeiro nível de observação comporta uma parte de abstração. Assim, concordo com as ideias de Massa (1994) e com as implícitas no trabalho de Leveson (1988) de que uma descrição em curso não será acrescida de detalhes se não definirmos, previamente, classes conceituais para se constituírem (ou evoluírem a partir das existentes) como referências das abstrações e generalizações a serem construídas. Em meu caso, apostava que o padrão espaço-temporal seria uma classe conceitual de referência. Ora, esse padrão, como outro qualquer, é 
produto de uma teoria que visa orientar o nosso olhar da natureza. Como decorrências para o ensino, precisamos captar as classes conceituais mais frutíferas a um contexto de aprendizagem nas teorias e conteúdos a serem ensinados. Foi o que tentei fazer durante toda a aula debate, como foi, também, a minha intenção didática ao desenvolver o discurso mais histórico não utilizado espontaneamente pelos alunos, a partir da discussão orientada e compartilhada da análise de um modelo. Pretendia partir de algo acontecido para explicar as suas possíveis causas, ou seja, o nosso caminho seria do efeito para a causa provável. A aglomeração é perceptiva no modelo, representa o acontecido, o efeito, pois então, pretendia que, a partir dessa primeira percepção, os alunos construíssem a sua causa: atração gravitacional. A quarta dimensão, o tempo, é representada pelos quadrinhos que dão a noção sequencial temporal: o contínuo; já a junção deste artifício com uma simplificada representação espacial permite o entendimento do padrão: explosão $\rightarrow$ aglomeração.

O modelo é, então, uma configuração global a ser inicialmente percebida. O trabalho com a percepção global visa o desenvolvimento do uso da intuição, que poderá facilitar operações mentais com modelos e padrões pelos papéis do referente, do contexto e da síntese. Esses modelos e padrões, em uma certa medida, podem ser considerados como 'gestaltens' que, potencialmente, se tornam suportes lógicos que estruturam o pensamento (estrutura de suporte em Bruner e Haste, 1990). Daí, naquela parte da aula debate, ao decifrarmos o modelo pela linguagem verbal, procurava enfatizar a compreensão dos padrões e raciocínios espaciais para, assim, contribuir para o desenvolvimento da capacidade dos alunos de fazerem conexões e raciocínios sobre bases abstratas, e desenvolverem a narrativa causal e os raciocínios de causalidade.

A atividade 4 buscava sistematizar os conceitos desenvolvidos na aula debate e junto com a solicitação da narração e do desenho sobre a formação do Universo, incluía os principais conceitos do tema discutidos em sala que deveriam ser utilizados pelos alunos na realização da tarefa. Desse modo, a atividade 4 consistia em: 1. Escreva uma estória da origem do Universo até a formação do Sistema Solar, utilizando as palavras ou frases seguintes: nuvem cósmica brilhante, explosão, galáxias, expansão, matéria comprimida com alta pressão e temperatura, Sistema Solar, atração gravitacional e movimento rotatório, e resfriamento e choque de partículas sólidas. 2. Represente sua história por meio de um desenho. Então, a seguir, trato de duas das produções dos alunos. 
Narração e desenho como expressões das ideias dos alunos sobre a formação do Universo

Escolhi as estórias de dois alunos: Juliano e Tábata. Elas não são representantes de outras entre as 18 estórias, pois cada uma delas é singular e própria, dificultando a escolha, mesmo que o objetivo fosse escolher estórias apenas parecidas com outras. Elegi aquelas que poderiam facilitar meu intento proposto neste artigo, conforme o subitem expressa. A seguir, as duas estórias escolhidas. A grafia e os desenhos foram mantidos como os alunos fizeram, apenas a grafia foi digitada para facilitar a leitura.

Juliano (idade: 11 anos)

"O universo surjiu de uma nuvem brilhante de poeira cosmica que foi se comprimindo e com auta preção e temperatura que se esplodiu formando bolas de materia que a atração gravitacionau e o movimento rotatorio formaram as galaxias e os sistemas solares que foi resfriando as bolas de materia e se aredondando formando os planetas."

Figura 3: Desenho do aluno Juliano sobre a formação do Universo

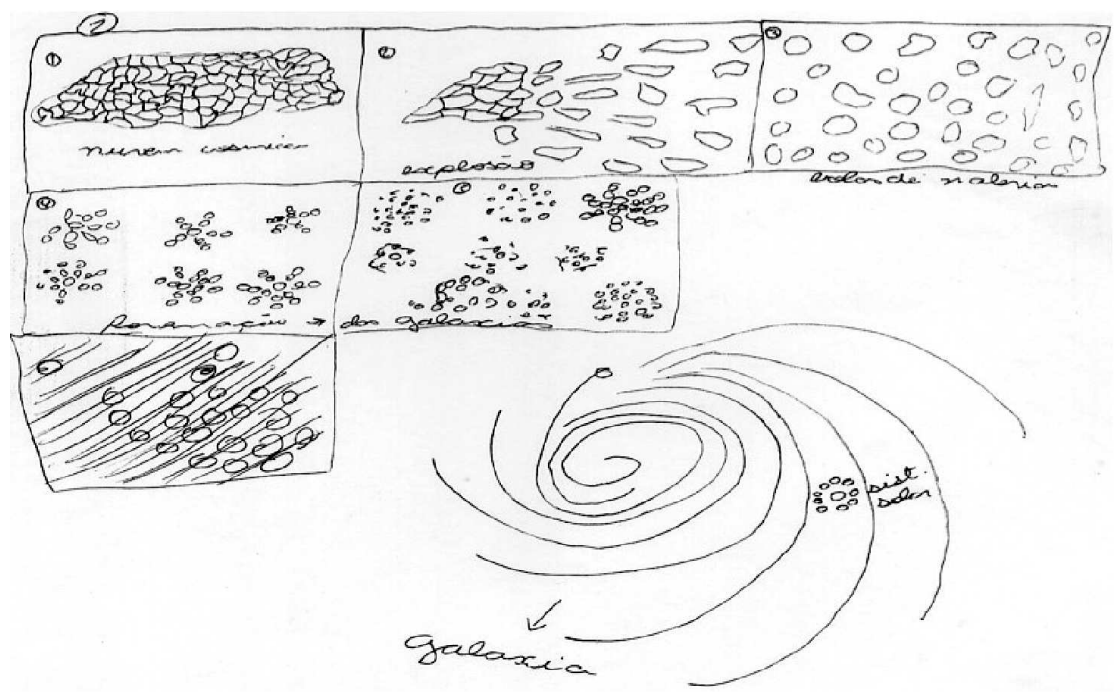

Tábata (idade: 11 anos)

"Ouve uma explosão de um meteoro grandissímo que expludiu e lançou seus pedacinhos para todo o canto do universo. E esses pedacinhos foram atraidos para um pedaço de meteoro muito atraente que puxava os outros pedacinhos que foram formando grandes bolas gigantes. 
Essas bolas gigantes formaram galáxias.

E foram se formando mais e mais planetas que se expandiam, formando mais galáxias e planetas.

Existiu também uma nuvem brilhante de poeira cósmica que explodiu e suas poerias se espalharam e sentaram nos planetas e deu brilho a eles.

Esse grande meteoro que explodiu foi formado por matéria que se comprimiu com alta pressão e temperatura, e não aguentando explodiu.

Dessas galáxias também foram se formando os Sistemas Solares, dessa formação ouve muita atrasão gravitacional, que também ajudou nos movimentos rotatório que os planetas fazem, em torno do Sol etc."

Figura 4: Desenho da aluna Tábata sobre a formação do Universo
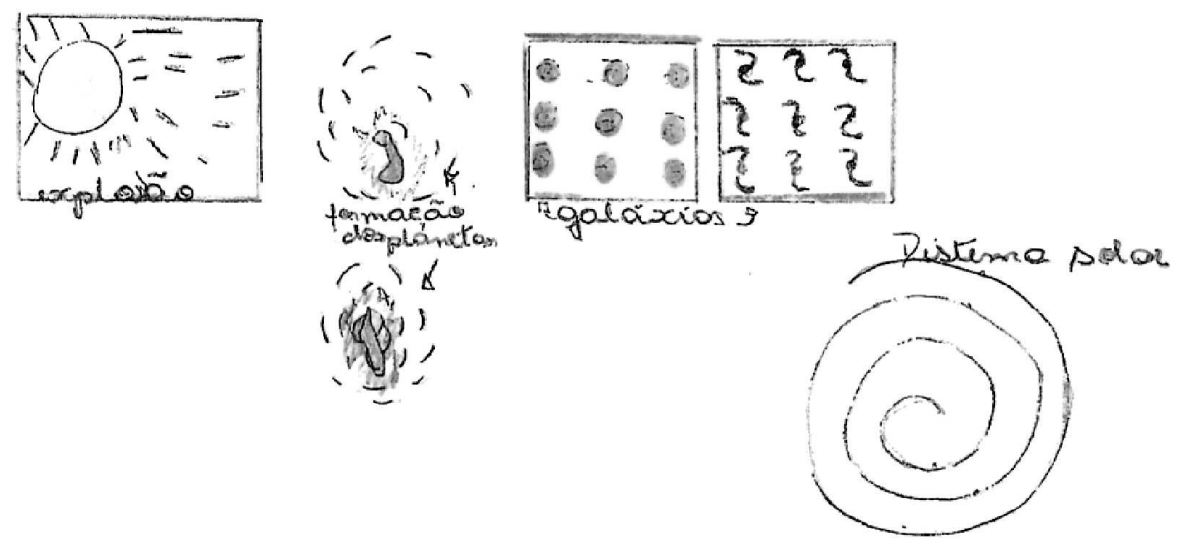

Elaborei o Quadro 1, onde as ideias prévias dos dois alunos e os sentidos elaborados durante as aulas foram sintetizados. Para tal síntese, parti das ideias de cada aluno antes da aula debate (ideias examinadas no questionário inicial) somente com referência à pergunta: Como surgiu o Universo? Em seguida, listei os problemas mais significativos que foram debatidos na aula, tentando identificar o que cada estória apresentou referente a eles. Tais problemas foram: o que explodiu e os efeitos da explosão (que estão ligados ao conceito organizador explosões), as causas da formação das galáxias, e como teria se formado o Sistema Solar (que estão ligados ao conceito organizador atração gravitacional). 
Quadro 1: Ideias prévias e sentidos elaborados nas sequências sobre a formação do Universo

\begin{tabular}{|c|c|c|c|c|c|}
\hline \multirow[t]{2}{*}{ ALUNOS } & \multirow{2}{*}{$\begin{array}{c}\text { IDEIAS PRÉVIAS } \\
\text { QUESTIONÁRIO INICIAL } \\
\text { Como surgiu o Universo? }\end{array}$} & \multicolumn{4}{|c|}{ Problemas mais significativos da aula } \\
\hline & & 0 que explodiu? & $\begin{array}{l}\text { Os efeitos da } \\
\text { explosão: }\end{array}$ & $\begin{array}{l}\text { As causas da } \\
\text { formação das } \\
\text { galáxias }\end{array}$ & $\begin{array}{l}\text { Como se formou o } \\
\text { Sistema Solar? }\end{array}$ \\
\hline Juliano & Explosão da nuvem brilhante & $\begin{array}{l}\text { Nuvem brilhante de } \\
\text { poeira cósmica que se } \\
\text { comprimiu e explodiu }\end{array}$ & $\begin{array}{c}\text { Expansão de bolas de } \\
\text { matérias }\end{array}$ & $\begin{array}{l}\text { A atração gravita- } \\
\text { cional e o movimento } \\
\text { rotatório juntaram as } \\
\text { bolas de matéria }\end{array}$ & $\begin{array}{c}\text { Continuação dos } \\
\text { processos anteriores e, } \\
\text { com o resfriamento, as } \\
\text { bolas de matéria foram } \\
\text { se arredondando, } \\
\text { formando os planetas }\end{array}$ \\
\hline Tábata & $\begin{array}{l}\text { Explosão de um grande meteoro } \\
\text { ou planeta }\end{array}$ & $\begin{array}{l}\text { Explosão de grande } \\
\text { meteoro causada pela } \\
\text { compressão, aumento } \\
\text { de pressão e temper- } \\
\text { atura da matéria } \\
\text { deste }\end{array}$ & $\begin{array}{c}\text { Milhares de } \\
\text { pedacinhos foram } \\
\text { espalhados e estes } \\
\text { foram puxados por um } \\
\text { meteoro atraente for- } \\
\text { mando os planetas }\end{array}$ & $\begin{array}{l}\text { Pedaços de meteoros } \\
\text { muito atraentes pux- } \\
\text { avam os pedacinhos } \\
\text { formando grandes } \\
\text { bolas gigantes } \\
\text { (as galáxias) }\end{array}$ & $\begin{array}{l}\text { Nas galáxias também } \\
\text { foram se formando os } \\
\text { Sistemas Solares, } \\
\text { dessa formação houve } \\
\text { muita atração } \\
\text { gravitacional }\end{array}$ \\
\hline
\end{tabular}

No Quadro 1, pode-se notar que Juliano apresentou uma sequência próxima ao modelo dos professores (Figura 1). Dos dois alunos foi ele quem assimilou melhor o modelo como um todo e suas partes. Ele mostra grande criatividade ao ajustar suas ideias prévias com as ensinadas. Para ele o início era a nuvem cósmica, porém havia aprendido que a explosão inicial fora a partir de uma matéria comprimida e com alta temperatura. Assim, introduz dois quadrinhos (Qs) 1 e 2, que não estavam presentes no modelo dado, para mostrar que são as partes da matéria comprimida (nuvem cósmica dividida em partes e justapostas) que explodiram . Nota-se nos Qs 2 e 3 que são essas partes que se expandem e se tornam as bolas de matéria. Para ele, as bolas de matéria do Q3 formariam algo que seria semelhante à nuvem cósmica do modelo do professor (primeiro quadrinho do modelo na Figura 1). Sempre acompanhando pela narrativa escrita, então, semelhante aos Qs 2 e 3 do modelo, ele faz o Q4 e Q5 mostrando as bolas de matéria formando as galáxias. No seu desenho final (grande espiral, como uma galáxia), são as mesmas bolas de matéria que vão se arredondar compondo os planetas de nosso Sistema Solar dentro da galáxia.

Em toda a estória mostra raciocínio espacial, mas destaco uma maior acuidade quando se utiliza da representação de uma grande espiral para, dentro dela, localizar o Sistema Solar (bolinhas de matéria). Sobre a qualidade da narrativa, Juliano, faz uma narração com história em quadrinhos (HQ) e sua narrativa é sucessiva-causal. Pelos quadrinhos com suas figuras e suas legendas, lê-se a sucessividade dos fenômenos e a implicação lógica de causa e efeito entre os quadrinhos. É clara a unidade narrativa nestes, com cada um indicando e singularizando as mudanças espaciais em cada fenômeno.

Juliano mostra racionalidade e intuição. É intuitivo quando apresenta uma boa noção de contexto e síntese. O modelo funcionou como uma 'gestalten', ele soube introduzir dois novos Qs (1 e 2) e o desenho final da espiral para 
amarrar com sua narrativa e formular uma sequência completa até o Sistema Solar, conforme fora solicitado, sem quebras ou lacunas importantes. Ele mostra capacidade analítica quando monta as partes, isto é, os quadrinhos, de modo a expressar a continuidade dos fenômenos por meio, também, da continuidade espacial. Pois, os quadrinhos estão ligados por representações que indicam claramente a identidade da mesma figura entre os quadrinhos. Auxiliado pelos elementos invariantes (por exemplo, figuras do Q1 = figuras do Q2), podemos criar as imagens de ligação, e a sucessividade e a espacialidade dos fenômenos tem continuidade na mente de Juliano. As partes justapostas da nuvem cósmica tornam-se as bolas de matéria que continuam pelos quadrinhos formando as galáxias até transformarem-se nos planetas do Sistema Solar.

O central das ideias de Tábata aparece escrito no primeiro parágrafo. $\mathrm{O}$ que norteou a estória de Tábata foram suas ideias prévias. Na verdade, ela fez um ajuste, um encaixe de algumas das ideias ensinadas com as suas. No questionário inicial, no início das aulas, ela já havia escrito que a origem se deu a partir da explosão de um grande meteoro que espalhou seus pedacinhos no espaço sem estar em fogo. Desse modo, seu primeiro quadrinho desenhado ilustra essa explosão parecendo uma simbolização de divergência. No $4^{\circ}$ parágrafo escrito ela utiliza as ideias do professor para dizer que esse meteoro gigante foi formado por matéria comprimida e com alta temperatura. Ela teve um momento único na aula debate, quando expôs seu entendimento próprio da acreção na formação da Terra (o meteoro atraente...). Talvez, por isso, o evento mais importante, após a explosão e espalhamento, foi o meteoro atraente que, conforme o segundo desenho, foi atraindo os pedacinhos espalhados pela explosão formando os planetas. Depois então, ela utilizou os Q2 e Q3 do modelo científico para representar a formação das galáxias. Casando o escrito com os desenhos, esses pedacinhos formaram bolas gigantes (desenho 3) que foram formando as galáxias, espiraizinhas (desenho 4). Em seu segundo parágrafo, planetas e galáxias continuaram a ser formados. Em seguida, dessas galáxias foram se formando os sistemas solares. O Sistema Solar ela representou por uma grande espiral.

Pelo seu desenho, as galáxias e o Sistema Solar apresentam mesma forma, mas são de tamanhos diferentes, sendo o Sistema Solar maior. Esse foi o modo que ela, provavelmente, encontrou para representar o problema da escala espacial. Tábata faz uma narração com ilustrações e sua narrativa é sucessivacausal. Desvendar a unidade narrativa necessita de uma maior atenção, já que sua narrativa escrita é muito detalhada e, praticamente, utiliza os desenhos como ilustrações da parte escrita, sendo as legendas muito sintéticas. Essa dificuldade se deve porque, na parte escrita, ela muitas vezes retorna um ponto inicial para explicá-lo melhor e, também, porque os desenhos não apresentam uma sucessividade clara pelos elementos invariantes. Apenas pela leitura dos desenhos, pareceria que eles estariam soltos e sem interligação.

A estória de Tábata é marcadamente diferente da outra. Ela usou o raciocínio intuitivo, encaixando algumas das ideias ensinadas para explicar 
melhor sua peculiar ideia de formação do Sistema Solar. Com boa capacidade de síntese e do contexto da narrativa ela ajustou a explosão do meteoro, meteoro atraente, formação dos planetas, formação das bolas gigantes e galáxias, finalizando na formação do Sistema Solar. Diferente de Juliano seu lado racional, analítico aparece melhor na escrita que no desenho. Ela cria parágrafos próprios para explicar e amarrar melhor as partes já escritas. Como já foi dito, os desenhos sem a parte escrita não formam uma sequência narrativa claramente legível Uma maior capacidade de abstração foi desenvolvida pelos dois alunos, por exemplo, no sentido da divergência para as explosões (a Figura 2 havia sido omitida na aula), uma vez que Tábata em seu Q1 apresenta indícios de simbolização quando representa a divergência para a explosão e Juliano o faz nos seus Q1 e Q2. O modelo de convergência (Figura 1) os ajudou em possíveis 'traspassos' analogamente entre as simbolizações da explosão-divergência para a acreção-convergência.

Finalizando, pode-se afirmar que as duas estórias apresentam uma unidade narrativa entre a escrita e o desenho, sem quebras ou incongruências. São estórias da formação do Universo até o Sistema Solar mais próxima da versão 'oficial' (Juliano) ou não (Tábata). Apesar de estórias diferentes, foi o raciocínio intuitivo de ambos que lhes deu condições para apresentar sequências narrativas mais completas, fortemente baseadas na assimilação do padrão espaço-temporal ensinado. Nota-se que o padrão de suas estórias é semelhante ao ensinado. O padrão dos quadrinhos de Juliano é: explosão-expansão $\rightarrow$ atração gravitacionalaglomeração. O padrão do desenho de Tábata é: explosão-expansão $\rightarrow$ meteoro atraente-aglomeração.

\section{Considerações Finais}

Sempre para esse nível escolar, o estudo de caso mostrou-me vínculos importantes entre a narração cotidiana e a narração histórica e a astronômica/geocientífica. Mostrou-me também que é possível o desenvolvimento de raciocínios de causa e efeito pelo uso de narrativas e modelos. Obviamente, isso foi possível por meio da dinâmica discursiva instaurada na classe pelo professor. O discurso e o contexto do discurso forçaram, colaboraram para desenvolver esses raciocínios peculiares, no caso, de Astronomia. Isso reforça as ideias do livro coordenado por Scott (1992): a narrativa faz parte da linguagem da criança desde as suas primeiras tentativas de comunicação; enfatizar o discurso narrativo das ciências auxilia os alunos a explicarem e a interpretarem melhor os problemas a serem enfrentados, bem como clarifica suas próprias ideias, já que a narração é uma autêntica e familiar forma de linguagem.

Não tenho dúvidas que foi fundamental o trabalho com o modelo para o desenvolvimento dos raciocínios mais peculiares em Astronomia. Com a introdução do modelo em quadrinhos sobre a formação das galáxias, esses raciocí- 
nios adquiriram um suporte lógico para evoluírem. A própria ordem da leitura dos quadrinhos, um após o outro, envolveu o conceito de tempo, de sucessão, de um antes e um depois. Com as imagens representando a suposta evolução de um evento, formou-se uma narrativa sucessiva. Então, a utilização espontânea por alguns alunos das HQs em suas estórias foi uma decorrência 'natural', e indicativa de um aprendizado importante, qual seja, a da transformação do modelo em quadrinhos em uma narrativa. Isso foi conseguido com a aparente e simples introdução das legendas, isto é, com o casamento das figuras com a linguagem escrita. $\mathrm{Na}$ verdade, alguns alunos criaram uma HQ a partir do modelo, e outros uma narrativa escrita com ilustrações. Ou seja, os alunos compreenderam e utilizaram toda uma vivência cotidiana com narrativas e HQs para se expressarem sobre o assunto em estudo.

Parecem-me inegáveis os avanços. De uma aula debate em que tínhamos um modelo em quadrinhos, surgiram verdadeiras narrativas com HQs ou desenhos. Foi um exercício da noção de sucessão no tempo, e das possíveis implicações causais de um evento. Foi o exercício do modelo mais sintético com suas partes, propiciando aos alunos raciocínios analíticos e sintéticos (intuição). Em outro artigo discuto esse tema com mais profundidade: Compiani (1998).

Com suas estórias, eu percebi que a linguagem escrita teve um papel mais descritivo no sentido de conduzir a narrativa, bem como, as legendas foram utilizadas sempre com o sentido de generalizar o evento representado no(s) quadrinho(s). Já os desenhos se incumbiram de singularizar e concretizar a narrativa pelas figuras representativas dos eventos, ou de um elemento importante da formação do Universo. Foi possível mostrar como os alunos, com o suporte lógico dado, mostraram criatividade ao não perderem de foco os processos de formação do Universo articulados com os agentes, ou seja, capacidade abstrativa sintética ou intuição. Do ponto de vista do raciocínio analítico, eles se depararam com o problema de como salientar o objeto (nuvem, galáxias etc.) da própria caracterização dos processos da sequência de eventos. Do ponto de vista do raciocínio intuitivo, exercitaram os problemas decorrentes da representação espacial das figuras (contorno, fundo), da escolha das figuras que fossem representativas dos eventos a serem sequenciados, e a capacidade abstrativa do modelo como um todo. Trabalhando indissociavelmente esses dois tipos de raciocínios, eles criaram suas estórias. Nessas generalizações está o cerne do artigo e, mesmo que inicial, há contribuições para o papel do verbal e não-verbal no processo de contextualização e descontextualização de sentidos nos discursos de sala de aula. Em outro artigo discuto esse tema com exemplos dos fenômenos não visíveis do ciclo da água (COMPIANI, 2000).

Finalizando, acredito que boa parte dessa mediação de elaborar e aplicar modelos em quadrinhos sucessivos, que embutem padrões espaço-temporais, para representar eventos com gigantescas escalas espaciais e temporais, possa ser generalizada, a princípio, para outros eventos e fenômenos como, por exemplo, a formação de montanhas, deriva dos continentes etc. Todos esses fenômenos 
naturais podem ser desmembrados em quadrinhos (estes em si indicarão a cronologia) com figuras representativas dos eventos mais significativos do fenômeno. Em decorrência do estudo feito, está aí, uma sugestão de aplicabilidade mais geral para outros temas tratados no ensino fundamental.

\section{NOTAS}

1 Coloco Astronomia/Geociências pois apesar do tema principal desenvolvido ter sido sobre Astronomia, por ser geólogo utilizei a base epistemológica dessa ciência para ensinar o tema "A Formação do Universo", o que diferencia o ensino ministrado já que usualmente são físicos os professores de Astronomia.

2 Para mim, sem dúvida, nos mais criativos raciocínios geológicos a parte correspondente aos processos intuitivos é de fundamental importância. Como exemplo, quando da elaboração da teoria da Deriva Continental, Wegener tinha uma perfeita noção das semelhanças geográficas entre América do Sul e África, da distribuição paleobiogeográfica dos fósseis entre os continentes. Ou seja, da distribuição espaco-temporal dos fósseis e das semelhanças geométricas do encaixe entre os dois continentes. Cálculos e medidas não desempenhavam parte importante desses atos de reconhecimento. Estes foram exercícios da capacidade humana de apreciar, comparar e contrastar formas. A aparência chamou a atenção humana antes de existir alguma teoria para explicá-la. A teoria surgiu para explicar o senso intuitivo das formas.

3 Isso de modo geral, uma vez que sobre os fenômenos geológicos que ocorrem na atualidade e são passíveis de observação, como terremotos, vulcanismos etc., pode-se identificar as causas com alguma precisão.

4 As seguintes etapas de trabalho e de coleta de dados foram desenvolvidas com o tema "A Formação do Universo": 1. questionário inicial para identificação das ideias prévias dos alunos sobre o tema; 2. trabalho em grupo dos alunos sobre suas respostas aos questionários; 3 . aula debate com os alunos sobre suas respostas aos questionários; 4. atividade prática (narração e desenho): 'a história da formação do Universo'. Posteriormente, antes da próxima atividade, foi entregue aos alunos o texto "A origem do Universo: teoria da grande explosão Big Bang"; 5. aula expositiva: 'origem do Sistema Solar'; e 6. avaliação final do tema realizada por meio de um questionário.

5 É um modelo composto por relações, símbolos que pretendem representar os processos supostos. Estas representações não estão ligadas fisicamente (no sentido de não serem reproduzíveis) aos objetos que dizem representar tampouco aos processos que originaram as galáxias.

\section{REFERÊNCIAS BIBLIOGRÁFICAS}

ARNHEIM, R. Arte e percepção visual: uma psicologia da visão criadora. São Paulo: $2^{\mathrm{a}} \mathrm{ed}$, Pioneira e EDUSP, 1980, 503p.

ARNHEIM, R. Intuizione e intelletto. Milano: Feltrinelli Ed, 1987, 374p.

BEZZI, A. Water cycle and constructivism: some "epistemologial" speculations. Cadernos do IG/UNICAMP. Campinas, v. 5, n.1, p. 31-46, 1995.

BEZZI, A. Is Geology teaching also Geology learning? An interactive education approach to solve the dilemma. In: Stow, D.A.V. and McCall, G.J.H. Geoscience Education and Training - In Schools and Universities, for Industry and Public Awareness. Rotterdam: A.A. Balkema, 1996.

BRUNER, J. \& HASTE, H. La elaboración del sentido. Barcelona: Ed. Paidós, 1990, 189p.

CAGNIN, A.L. Os quadrinhos. São Paulo: Ática, 1975, 239p.

COMPIANI, M. Geologia pra que te quero no ensino de ciências, Educação \& Sociedade, Campinas, n. 36, p. 100-117, 1990.

COMPIANI, M. (1996) As Geociências no ensino fundamental: um estudo de caso sobre o tema "A formação do Universo". Campinas: FE/UNICAMP, 216p. (Tese de doutorado).

COMPIANI, M. A narrativa histórica das Geociências na sala de aula no ensino fundamental. In: 
ALMEIDA, M. J. P. M. de \& SILVA, H. C. da (Orgs.). Linguagens, leituras e ensino da ciência. Campinas: Mercado de Letras, 1998, cap. 9, pp. 163-182.

ALMEIDA, M. J. P. M. Linguagens e as Geociências no ensino fundamental. In: ALMEIDA, M. J. P. M. de \& SILVA, H. C. da (Orgs.) Textos de palestras e sessões temáticas: III Encontro de Linguagens, Leituras e Ensino da Ciência no $12^{\circ}$ COLE. Campinas, SP: Graf. FE/UNICAMP, 2000, pp. 43-60.

ALMEIDA, M. J. P. M. Linguagem e percepção visual no ensino de Geociências. Pro-posições, v. 17, n. 1 (49), p. 85-104, 2006.

COMPIANI, M. \& PASCHOALE, C. Geologia como forma de conhecimento sintético e histórico sobre o planeta e sua adequação ao ensino de Ciências. In: SIMP. ENS. GEOL., 6, Tenerife Espanha, 1990. Anais...Universidad de la Laguna, Tenerife, 1990, p. 21-33.

FRODEMAN, R. (1995) Geological reasoning: Geology as an interpretive and historical science. GSA Bulletin, v. 107, n. 8, p. 960-968.

HODSON, D. Philosophy of science, science and science education. Studies in Science Education, University of Leeds, v. 12, p. 2557, 1985.

LEVESON, D. J. The Geologist's Vision. J. Geological Education, v. 36, p. 306-309, 1988. (Tradução Vívian Branco Newerla).

LOVRETO, J. A. A linguagem do futuro. In: ALVES, M.L. \& DURAN, M.C.G. (Coord.) Linguagem e linguagens. São Paulo: FDE, 1993, p. 65-76. (Série ideias, n.17).

MACHADO, C. M. C.; VEIGA FILHO, A. A.; GATTI, E. U. \& SANTAELLA BRAGA, M. L.

Critérios para a divulgação da pesquisa científica: uma aplicação da semiótica peirceana. São Paulo: Inst. de Economia Agrícola da Sec. de Agricultura e Abastecimento do Estado de São Paulo, 1984, 69p. (Série Relatórios de Pesquisa 4/84).

MASSA, B. La adquisición precoz de conceptos abstractos: algunas consideraciones sobre la observación en geología. Enseñanza de las Ciencias de la Tierra, Madrid, nº extra, p. 34-39, 1994. (Comunicaciones, 8 SIM. ENS. GEOLOGÍA, Córdoba, 1994).

NOVAK, J. D. El constructivismo humano: hacia la unidad en la elaboración de significados psicológicos y epistemológicos. In: PORLAN, R.; GARCIA, J. E. \& CANAL, P. Constructivismo y enseñanza de las ciencias. Sevilla: Diada Ed, 1988, p. 23-40.

ORION, N. An holistic approach to introducing geosciences into schools: The Israeli model-from practice to theory. In: Stow, D.A.V. and McCall, G.J.H. Geosciences Education and Training - In Schools and Universities, for Industry and Public Awareness. Rotterdam: A.A. Balkema, 1996, p. 17-34.

PASCHOALE, C. Alice no país da geologia e o que ela encontrou lá. In: CONGR. BRAS. GEOL., 33, Rio de Janeiro, 1984. Anais...Rio de Janeiro, SBG, v. 5, p. 242-249, 1984.

PASCHOALE, C. Montando um discurso da Terra. Apostila, FEL/UNICAMP, 1988, 10p.

PASCHOALE, C. Geologia como Semiótica da Natureza. São Paulo: PUC/SP, Dissertação de Mestrado, 1989, 138p.

PASCHOALE, C. Dupin geólogo? Uma abordagem semiótica para a geologia e o conto policial. In: LOPES, M. \& FIGUEIRÔA, S. (Org.) O conbecimento geológico na América Latina: questões de história e teoria. Campinas: UNICAMP - Instituto de Geociências, 1990, p. 241-258.

PEDEMONTE, G. M. \& BEZZI, A. Geology and Society in education: a multifaceted problem calling for broader research prospects. In: INTERN. GEOL. CONGRES., 28, Washington DC, 1989. (mimeografado).

PINO, A. O conceito de mediação semiótica em Vygotsky e seu papel na explicação do psiquismo humano. Cadernos Cedes, Campinas, n. 24, p. 3243, 1991.

PONTECORVO, C.; AJELlO, A. M. \& ZUCCHERMAGLIO, C. Discutendo si impara. Roma: Nuova Italia, 1992, 266p.

ROGERS, R. D. Timespace patterns: the natural laws of geology. History of Geology, v. 2, n. 1, p. 38-40, 1983.

ROGERS, R. D. Use of observational patterns in geology. Geology, v. 17, p. 131-134, 1989.

RODRÍGUEZ, M.; VILLA, S. \& ANGUITA, F. Ciencias Naturales $1^{\circ}$ BUP. Madrid: Ed.SM, 1990, 381p. 
SANTAella BRAGA, M. L. Produção de linguagem e ideologia. São Paulo: $2^{\mathrm{a}}$ ed, Cortez Ed, 1980, 160p.

SANTAELLA BRAGA, M. L. O que é semiótica. São Paulo: Ed. Brasiliense, 1984, 114p.

SCOTT, J. (ed.) Language and science links: classroom implications. Australian Reading Association, 1992, 91p.

VICKERS, G. Rationality and intuition. In: WECHSLER, J. (Ed.) On aesthetics in Science. $2^{\text {nd }}$ ed. The Massachusetts Institute of Technology, 1979, p. 143-164.

VYGOTSKY, L.S. Immaginażione e creatività nell'età infantile. Roma: Ed. Riuniti, 1990, 142p.

WERSTCH, J. V. \& MINICK, N. The problem of meaning in a sociocultural approach to mind. Paper presented at the University of Calgary lectures series "Theoretical Advances in the Study of Cognition”, 1988. 